\title{
Avaliação de produtos químicos comerciais, in vitro e in vivo, no controle da doença foliar, mancha branca do milho, causada por Pantoea ananatis.
}

\author{
Cleide Aparecida Bomfeti ${ }^{1}$, Walter Fernandes Meirelles ${ }^{2}$, Edneia Aparecida Souza-Paccola ${ }^{1}$, Carlos Roberto Casela ${ }^{2}$, \\ Alexandre da Silva Ferreira², Ivanildo Evódio Marriel ${ }^{2}$ e Luzia Doretto Paccola-Meirelles ${ }^{1}$
}

${ }^{1}$ Universidade Estadual de Londrina, CCB/BIO, CP 6001, 860051-990 Londrina/PR. paccola@ @el.br; ${ }^{2}$ Embrapa Milho e Sorgo, CP 151, 35701970 Sete Lagoas/MG. casela@cnpms.embrapa.br

Data de chegada: 25/11/2004. Aceito para publicação em: 15/09/2006.

\section{RESUMO}

Bomfeti, C.A; Meirelles, W.F; Souza-Paccola, E.A.; Casela, C.R.; Ferreira, A.S.; Marriel, I.E.; Paccola-Meirelles, L.D. Avaliação de produtos químicos comerciais, in vitro e in vivo no controle da doença foliar, mancha branca do milho, causada por Pantoea ananatis. Summa Phytopathologica, v.33, n.1, p.63-67, 2007.

Uma bactéria identificada como Pantoea ananatis foi recentemente isolada de lesões jovens da doença mancha branca do milho de plantas naturalmente infectadas. Esta bateria reproduziu sintomas semelhantes aos da doença quando inoculada em plantas de milho em casa de vegetação. Estudos anteriores realizados por outros autores demonstraram que o controle desta doença em condições de campo foi obtido pelo uso de fungicidas, principalmente o Mancozeb, nas fases iniciais de seu desenvolvimento. O objetivo deste estudo foi avaliar a freqüência de isolamento da bactéria $P$. ananatis a partir de plantas infectadas coletadas na região de Londrina, Estado do Paraná, e reproduzir sintomas da doença através de inoculações artificiais em plantas de milho em casa de vegetação. Utilizando os produtos químicos testados anteriormente por outros autores para o controle desta doença a campo, foi também objetivo deste trabalho avaliar o potencial destes produtos na inibição da bactéria tanto em condições de laboratório como em condições de infecção natural. Os resultados mostraram que $P$. ananatis foi isolada em $40 \%$ das lesões jovens coletadas a campo e quando inoculada em casa de vegetação sob condições controladas reproduziu sintomas semelhantes aos observados a campo. Entre os produtos químicos testados, o fungicida Mancozeb mostrou-se eficiente no controle da doença a campo, em concordância com os relatos anteriores. Este produto inibiu completamente o crescimento da bactéria em laboratório, explicando os resultados obtidos a campo. Os demais produtos não foram eficientes no controle a campo e eles também não inibiram a bactéria em laboratório. Estes resultados representam evidências adicionais de que a bactéria $P$. ananatis é o agente causal da doença mancha branca do milho.

Palavras - Chave adicionais: fungicida; Erwinia ananas; controle químico; mancha foliar de phaeosphaeria.

\section{ABSTRACT}

Bomfeti, C.A; Meirelles, W.F; Souza-Paccola, E.A.; Casela, C.R.; Ferreira, A.S.; Marriel, I.E.; Paccola-Meirelles, L.D. Evaluation of commercial chemical products, in vitro and in vivo in the control of foliar disease, maize white spot, caused by Pantoea ananatis. Summa Phytopathologica, v.33, n.1, p.63-67, 2007.

A bacterium identified as Pantoea ananatis was recently isolated from young lesions of the disease maize white spot from infected plants in the field. This bacterium produced similar symptoms of the disease when inoculated on maize plants in greenhouse. Previous studies carried out by other authors demonstrated that the control of this disease in field conditions has been achieved through the use of fungicides mainly with the Mancozeb in the initial phases of its development. The aim of this study was to evaluate the frequency of isolation of $P$. ananatis from infected plants in the region of "Londrina, Paraná State" and to reproduce symptoms of the disease through artificial inoculation of maize plants in greenhouse. Using the chemical products tested previously by other authors for the control of this disease in the field, it was also objective of this work to evaluate the potential of these products to inhibit the bacterium, at both in laboratory and in condition of natural infection. The results showed that $P$. ananatis was successfully isolated from $40 \%$ of the young lesions collected in the field and when inoculated in greenhouse (controlled conditions), it reproduced symptoms similar to what was observed in the field. Among the tested chemical products, the fungicide Mancozeb was the best in the control of the disease under field conditions, in agreement with previous reports. This product inhibited completely the bacterium in laboratory, explaining the results found in the field. The others products were not efficient to control the disease and they did not also inhibit the bacterium in laboratory. The results represent additional evidences that the bacterium $P$. ananatis is the causal agent of the maize white spot disease.

Additional keywords: fungicide; Erwinia ananas; chemical control; phaeosphaeria leaf spot. 
Uma doença causando manchas foliares em milho, instalou-se no Brasil na década de 80 e foi identificada (3) como sendo a mesma doença descrita por Rane et al. (15), a mancha foliar de Phaeosphaeria, causada pelo ascomiceto Phaeosphaeria maydis (P. Henn.) Rane Payack e Renfro (sin. Sphaerulinia maydis = Leptosphaeria zeae maydis), forma anamórfica Phyllosticta sp. Também conhecida como Pinta Branca do milho ou Mancha Branca do Milho não era de importância no Brasil, porque ocorria no final do ciclo da cultura, porém atualmente, tem sido considerada como uma das principais doenças da cultura, e hoje encontra-se disseminada em praticamente todas as regiões produtoras de milho (4). Os sintomas iniciam-se pelo aparecimento, nas folhas, de manchas cloróticas aquosas do tipo anasarca, as quais tornam-se necróticas de coloração palha. No centro das lesões necróticas podem ser visualizadas estruturas de reprodução do fungo, os pseudotécios e picnídios, segundo Fantim (3), ou peritécios e picnídios segundo Pinto et al.(14) e Fernandes \& Oliveira (5). Em condições favoráveis ao seu desenvolvimento, a doença pode causar seca prematura das folhas com redução do ciclo da planta e quedas acentuadas no tamanho e peso dos grãos (14). Estudos de caracterização isoenzimatica e por RAPD feitos por Cervelatti et al. (1) em isolados fúngicos oriundos de picnídios e pseudotécios, mostraram que estas estruturas reprodutivas pertencem a espécies fúngicas diferentes e não aos estados anamórficos e teleomórficos de um mesmo agente causal.

Pinto \& Fernandes $(13)$ e Pinto $(9,10,11)$ avaliaram a ação de vários fungicidas no controle da doença. Dentre os produtos avaliados, o oxicloreto de cobre e o Mancozeb mostraram-se eficientes; entretanto o oxicloreto de cobre apresentou efeito fitotóxico. De acordo com Pinto (10,11), o controle efetuado por Mancozeb resultou em aumento de $63,1 \%$ na produção de grãos em relação à testemunha sem fungicida.

Pinto (9) e Pinto \& Fernandes (13) verificram que plantas de milho tratadas com o fungicida Benomyl, em condições naturais de infecção, apresentaram sintomas da doença, porém observou que as lesões formadas eram destituídas de estruturas reprodutivas fúngicas. Pinto (9) concluiu que este produto, com relação a esta doença, tem ação fungistática e não fungicida, pois afetou apenas a formação das estruturas de reprodução. Os resultados destes trabalhos colaboraram em parte com a hipótese inicial de que a doença seria causada por um agente fúngico.

Recentemente, Paccola-Meirelles et al. (7), isolaram uma bactéria, identificada como Pantoea ananatis (syn. Erwinia ananas), a partir de lesões de estágio inicial da mancha foliar de Phaeosphaeria, em uma freqüência de $63 \%$. Esta bactéria, quando inoculada em plantas de milho reproduziu, em casa de vegetação, sintomas semelhantes aos da doença a campo. A bactéria foi reisolada a partir das lesões, concluindo assim os postulados de Koch. Os autores demostraram ser a bactéria o agente causal da doença e não um fungo como postulado inicialmente. Posteriormente, em experimentos de inoculações artificiais, PaccolaMeirelles et al. (8) avaliaram o comportamento de genótipos de milho, previamente conhecidos por suas reações contrastantes de resistência e suscetibilidade à mancha foliar de Phaeosphaeria, quando inoculados com a bactéria $P$. ananatis em condições de casa de vegetação e verificaram que as reações foram semelhantes àquelas observadas em condições de campo, reforçando assim o papel da bactéria como agente causal da doença.

O objetivo deste trabalho foi o de confirmar a freqüência de isolamento da bactéria $P$. ananatis a partir de plantas de milho cultivadas na região de Londrina/PR no Norte do Paraná, confirmar sua patogenicidade em casa de vegetação e avaliar seu comportamento, quando cultivada em presença de seis dos fungicidas testados anteriormente por Pinto $(9,10,11)$. A essa lista de agentes inibidores foi acrescentado o antibiótico Agrimicina e o fungicida Hidróxido de Cobre nos testes. Destes oito agentes, sete foram avaliados também a campo em condições de infecção natural sobre a cultivar HS200.

\section{MATERIAL E MÉTODOS}

Isolamento da bactéria e inoculação em plantas de milho em condições de casa de vegetação: Folhas de milho contendo lesões do tipo anasarca foram coletadas e lavadas com sabão neutro. A seguir, segmentos foliares contendo as lesões foram retirados das folhas, desinfectados com cloramina T $2 \%$ em água, durante 4 minutos e lavados 3 vezes em água destilada esterilizada durante 30 segundos cada lavagem. A água da última lavagem foi plaqueada em meio TSA (Triptic Soy Agar) e em meio PDA (Potato Dextrose Agar) para controle da metodologia de desinfestação. Com o auxílio de um bisturi esterilizado retiraram-se as bordas de cada segmento foliar. Parte das extremidades das lesões foi transferida para meio PDA acrescido de ampicilina $(2,5 \mu \mathrm{g} / \mathrm{mL})$ e parte para meio TSA acrescido de ciclohexamida $(50 \mu \mathrm{g} / \mathrm{mL})$, para isolamento de fungos e de bactérias, respectivamente (7).

Para os testes de patogenicidade em condições de casa de vegetação, foi selecionado ao acaso um isolado de $P$. ananatis obtido das lesões anasarcas. Uma suspensão bacteriana contendo $10^{6} \mathrm{UFC} / \mathrm{ml}$ em solução salina $0,1 \%$ foi pulverizada em folhas de milho da cv HS 200, sensível à doença, com 30 dias de idade, previamente injuriadas com esponja. Após a inoculação, as plantas foram colocadas em câmara úmida por 60 horas e, a seguir, em casa de vegetação até o aparecimento dos sintomas. Para controle, as plantas foram pulverizadas apenas com solução salina $0,1 \%$.

Crescimento "in vitro" da bactéria em presença de agentes inibidores: Avaliou-se a ação de oito produtos químicos sobre o crescimento bacteriano (Tabela 1). Com exceção do antibiótico Agrimicina e do fungicida Hidróxido de Cobre, os demais produtos foram selecionados com base nos trabalhos de Pinto $(9,10,11)$. Apesar destes agentes não serem recomendados para o controle da Mancha Branca do Milho, seguiu-se as recomendações do Compêndio de Defensivos Agrícolas - Guia Prático de Produtos Fitossanitários para Uso Agrícola (2) para outras doenças, sendo avaliadas também duas doses acima das recomendadas (Tabela 1). Uma alíquota de $0,1 \mathrm{~mL}$ de suspensão bacteriana, contendo $10^{6} \mathrm{UFC} / \mathrm{ml}$ foi plaqueada "pour plate" em placas de petri contendo $20 \mathrm{~mL}$ de meio TSA acrescido de diferentes doses de cada agente químico (Tabela 1). Foram feitas 20 repetições para cada tratamento e também para a testemunha, sem o produto químico. O crescimento bacteriano foi avaliado após 24 horas de incubação a $28^{\circ} \mathrm{C} \pm 2$ através da contagem (UFC) em placa.

Desenvolvimento da doença em condições naturais de infecção a campo: Com exceção do Benomyl, os demais agroquímicos listados na Tabela 1 foram também avaliados a campo, em parcelas da cv HS 200, sob condições de infecção natural. O experimento foi conduzido em 2002, no período de safrinha, na Embrapa Soja, em Londrina/PR. O modelo experimental foi o de blocos ao acaso, com três repetições. As parcelas foram constituídas por 4 fileiras de 4 metros de comprimento, com 2 fileiras centrais de área útil. Foram feitas três aplicações dos agentes químicos em intervalo de dez dias entre cada aplicação. A avaliação dos sintomas foliares foi realizada em plantas em estádio de maturação fisiológica (cerca de 100 dias após a semeadura), usando-se escala de notas de 0 a $9(0=$ ausência de lesões; 
Tabela 1. Fungicidas e antibióticos utilizados nos experimentos e respectivas doses.

\begin{tabular}{lcccc}
\hline Produtos & $\begin{array}{c}\text { Doses recomendadas } \\
\text { a campo* }\end{array}$ & \multicolumn{2}{c}{ Doses em Laboratório** } \\
\cline { 3 - 5 } & Dose I & Dose II & Dose III \\
\hline Oxitetraciclina+ streptomicina) (Agrimicina) & $3500 \mathrm{~g}$ & $0,135 \mathrm{mg}$ & $0,270 \mathrm{mg}$ & $0,405 \mathrm{mg}$ \\
Triadimenol & $750 \mathrm{~mL}$ & $0,025 \mu \mathrm{l}$ & $0,050 \mu \mathrm{l}$ & $0,075 \mu \mathrm{l}$ \\
Benomyl & $500 \mathrm{~g}$ & $0,020 \mathrm{mg}$ & $0,040 \mathrm{mg}$ & $0,060 \mathrm{mg}$ \\
Thiophanato metílico & $500 \mathrm{~g}$ & $0,020 \mathrm{mg}$ & $0,040 \mathrm{mg}$ & $0,060 \mathrm{mg}$ \\
Tebuconazole & $750 \mathrm{~mL}$ & $0,025 \mu \mathrm{l}$ & $0,050 \mu \mathrm{l}$ & $0,075 \mu \mathrm{l}$ \\
Hidróxido de Cobre & $2200 \mathrm{~g}$ & $0,085 \mathrm{mg}$ & $0,170 \mathrm{mg}$ & $0,255 \mathrm{mg}$ \\
Mancozeb & $2500 \mathrm{~g}$ & $0,095 \mathrm{mg}$ & $0,190 \mathrm{mg}$ & $0,285 \mathrm{mg}$ \\
Oxicloreto de Cobre & $700 \mathrm{~g}$ & $0,025 \mathrm{mg}$ & $0,050 \mathrm{mg}$ & $0,075 \mathrm{mg}$ \\
\hline
\end{tabular}

* ingrediente ativo ha ${ }^{-1}$

** por $\mathrm{mL}$ de meio de cultura

$1=$ lesões em $10 \%$ das folhas; $2=$ lesões em $20 \%$ das folhas; $3=$ lesões em $30 \%$ das folhas; $4=$ lesões em $40 \%$ das folhas; $5=$ lesões em $50 \%$ das folhas; $6=$ lesões em $60 \%$ das folhas; $7=$ lesões em $70 \%$ das lesões; $8=$ lesões em $80 \%$ das folhas; $9=$ lesões em $90 \%$ das folhas).

\section{RESULTADOS E DISCUSSÃO}

Os isolamentos obtidos a partir de lesões jovens mostraram a presença de uma bactéria de colônia lisa, com pigmentação amarela brilhante, em uma frequiência de $40 \%$, que foi identificada como $P$. ananatis e se mostrou patogênica em inoculações artificiais (Figura1), corroborando com os resultados obtidos anteriormente por PaccolaMeirelles et al. (7).

Diferentes fungos foram isolados em baixa frequiência, a partir das mesmas lesões. Estes resultados estão em concordância com aqueles apresentados por Paccola-Meirelles et al. (6), onde os autores, analisando 1284 lesões em 30 híbridos de milho super precoces e 1437 lesões em 49 híbridos precoces observaram que 79,3\% e 68,5\% das lesões necróticas dos híbridos super precoces dos híbridos precoces, respectivamente, não apresentaram estruturas reprodutivas fúngicas, sendo que o fungo $P$. maydis foi isolado em apenas 4,4\% dos genótipos analisados.

Os resultados obtidos dos experimentos "in vitro" sobre o comportamento da bactéria quando cultivada em presença dos produtos químicos mostraram que houve inibição total de seu crescimento na presença do Mancozeb (Tabela 2). A aplicação deste fungicida também resultou em controle eficiente da doença em condições de campo quando comparado com a testemunha (Figura 2), em concordância com os resultados obtidos por Pinto $(9,10$, $11,12)$. Os demais produtos avaliados permitiram o crescimento da bactéria em laboratório e não foram efetivos no controle da doença em condições de campo. O Oxicloreto de cobre mostrou-se altamente tóxico às plantas de milho nas dosagens utilizadas, como também descrito por Pinto (11) e Pinto \& Fernandes (13). O mesmo foi observado na aplicação de Hidróxido de cobre. Devido à alta fitotoxidade de ambos os agentes sobre as plantas de milho não foi possível atribuir notas a estes tratamentos, portanto estes não foram incluídos na Figura 2.

Como já citado anteriormente, Pinto (9) e Pinto \& Fernandes (13) consideraram o Benomyl como sendo um produto de ação fungistática e não fungicida, por inibir apenas a formação de

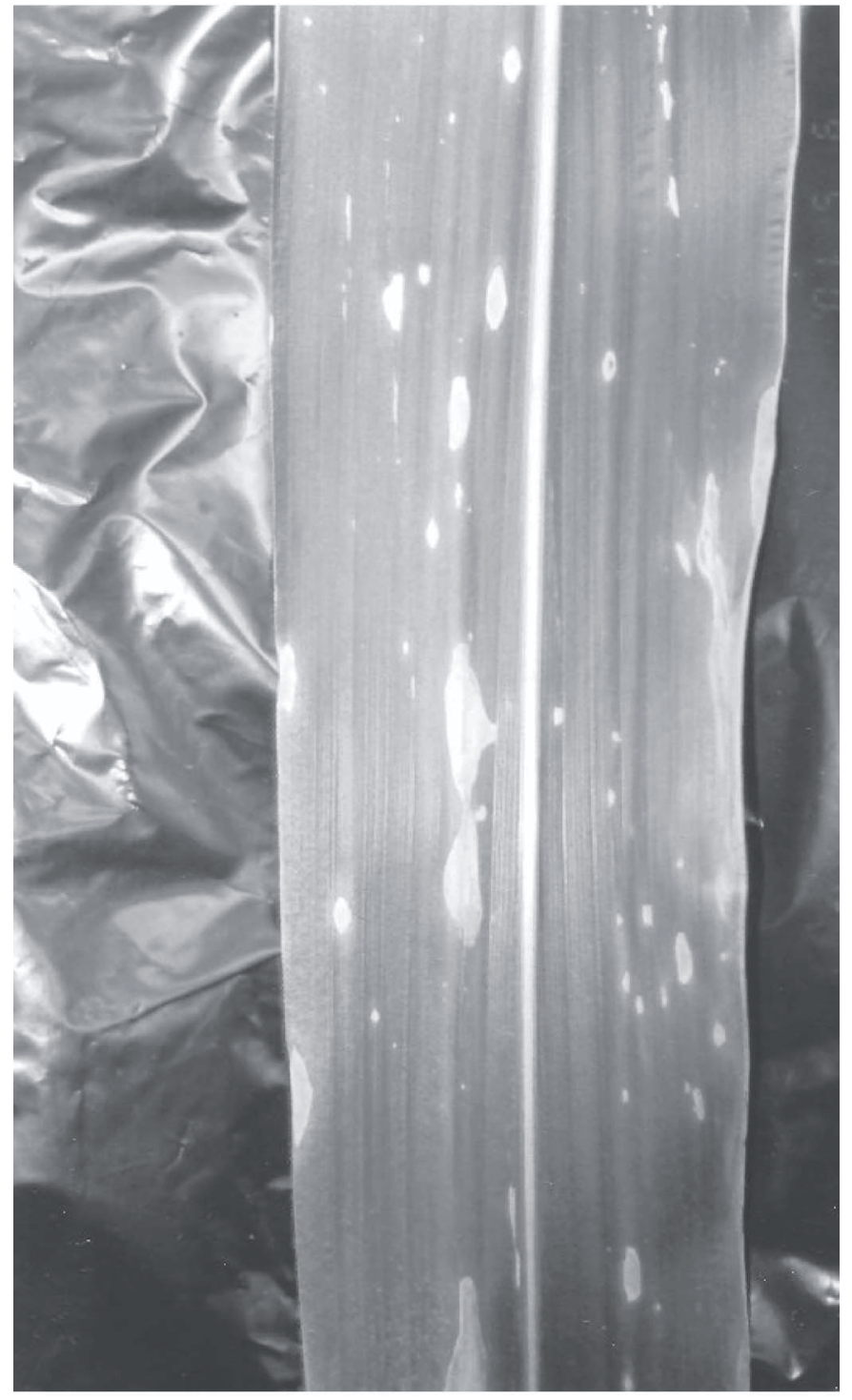

Figura 1. Folha de milho da cv HS 200 inoculada artificialmente com a bactéria em casa de vegetação, reproduzindo os sintomas da doença Mancha Branca do Milho. 


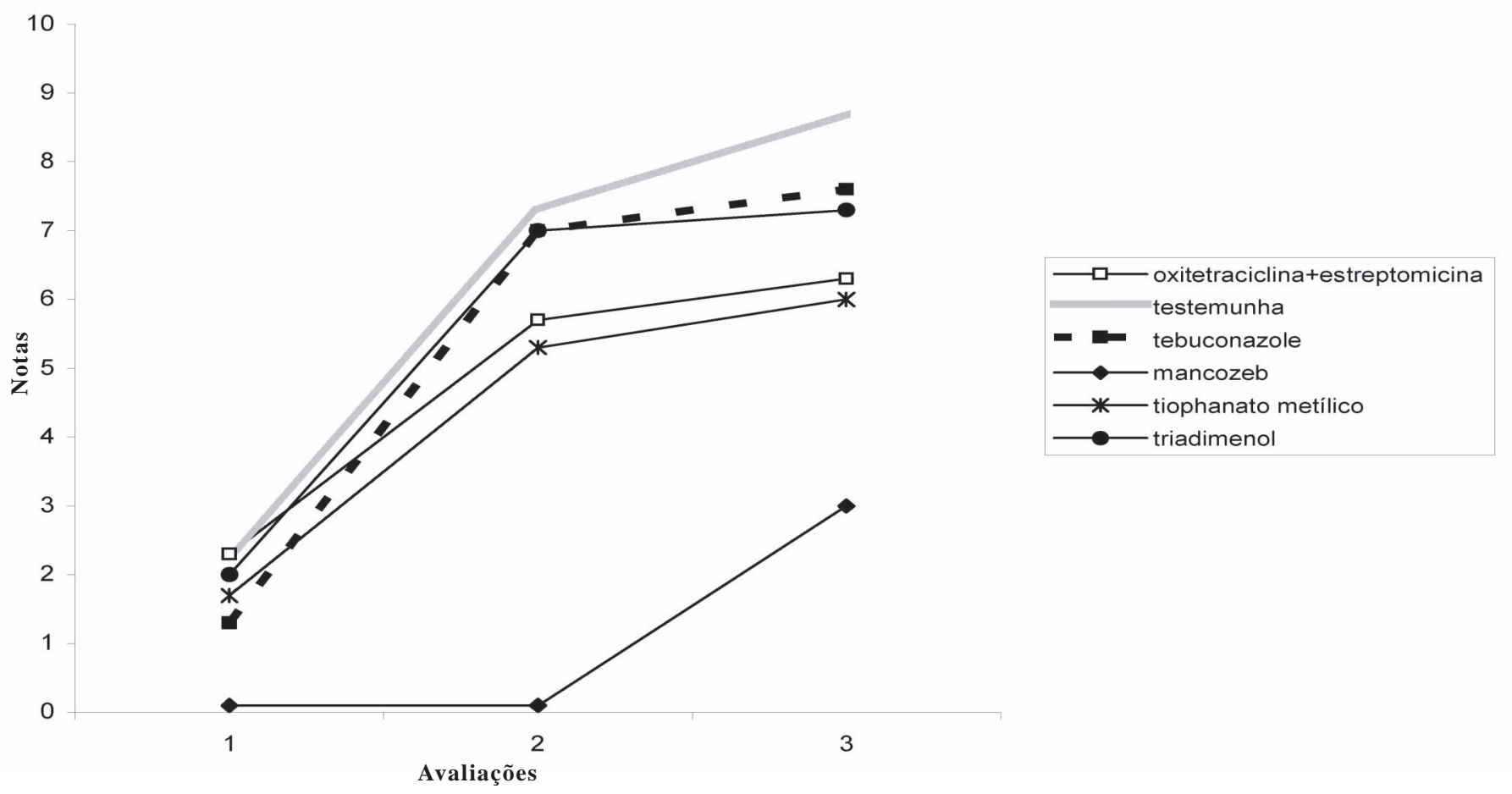

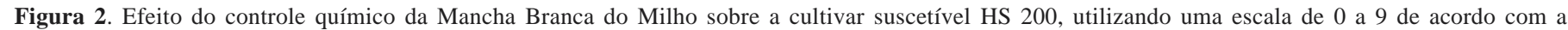
porcentagem de infecção observada nas folhas. Média de 3 repetições para cada tratamento, em 3 avaliações com intervalo de 10 dias entre elas.

Tabela 2. Comportamento de P. ananatis quando cultivada em presença de diferentes agentes químicos.

\section{Produtos}

Oxitetraciclina+ streptomicina (Agrimicina)

Triadimenol

Benomyl

Thiophanato metílico

Tebuconazole

Mancozeb

Oxicloreto de Cobre

Hidróxido de Cobre

Controle (meio de cultura sem o produto)

Crescimento bacteriano em meio sintético

Dose I

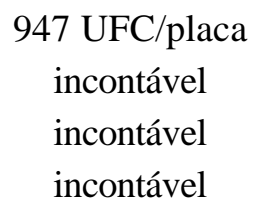

1038 UFC/placa

0

incontável

incontável

incontável
Dose II

896 UFC/placa

incontável

incontável

incontável

1283 UFC/placa

0

incontável

incontável

incontável
Dose III

$451 \mathrm{UFC} /$ placa

1182 UFC/placa

incontável

incontável

$1181 \mathrm{UFC} /$ placa

0

incontável

incontável

incontável estruturas reprodutivas fúngicas no centro das lesões necróticas. Nossos resultados contrariam a explicação dada por estes autores com relação a este fungicida. O Benomyl não impediu o crescimento de $P$. ananatis em laboratório. Desta forma as lesões foliares produzidas a campo em plantas tratadas com Benomyl foram produzidas pela bactéria, enquanto que os fungos, que posteriormente colonizam as lesões pré-estabelecidas pela bactéria, estes sim foram inibidos por este fungicida, impedindo a formação das estruturas reprodutivas fúngicas, as quais não puderam ser visualizadas por Pinto (9) e Pinto \& Fernandes (13) no centro das lesões necróticas.

Estes resultados representam uma evidência adicional de que o agente causal da doença Mancha Branca do Milho trata-se de uma bactéria e não um fungo como vem sendo reportado, sendo, portanto uma doença diferente daquela descrita por Rane et al. (15).

\section{REFERÊNCIAS BIBLIOGRÁFICAS}

1. Cervelatti, E.P.; Paiva, E.; Meirelles, W.F.; Casela, C.R.; Fernandes, F.T.; Teixeira, F.F.; Paccola-Meirelles, L.D. Characterization of fungal isolates from pycnidia and pseudothecia from lesions of Phaeosphaeria leaf spot in maize. Revista Brasileira de Milho e Sorgo, Sete Lagoas, v.1, n.3, p.30-37, 2002.

2. Compêndio de defensivos agrícolas: guia prático de produtos fitossanitários para uso agrícola. 6. ed. São Paulo: Andrei, 1999. 672 p.

3. Fantin, G.M. Mancha de Phaeosphaeria, doença do milho que vem aumentando sua importância. Biológico, São Paulo, v. 56, n. 1/2, p. 39, 1990/1994.

4. Fernandes, F.T.; Oliveira, E. Principais doenças na cultura do milho. Circular Técnica. Embrapa-CNPMS, Sete Lagoas - MG, n.26. p. 2680, 1997.

5. Fernandes, F.T.; Oliveira, E. Milho manchado é milho sem produção. Cultivar, Pelotas, ano I, n. 12, p. 38-39, 1999. 
6. Paccola-Meirelles L.D.; Meirelles, W.F.; Cervelatti, E.P.; Maki, C.S.; Casela, C.R.; Fernandes, F.T.; Ferreira, A.S. Caracterização morfológica das lesões da mancha foliar por Phaeosphaeria em híbridos de milho e avaliação da incidência do estágio sexuado e assexuado do patógeno. In: Congresso Nacional de Milho e Sorgo, 22., 1998, Recife. Anais... Sete Lagoas: Sociedade Brasileira de Milho e Sorgo, 1998. 1 CD-ROM.

7. Paccola-Meirelles, L.D.; Ferreira, A.S.; Meirelles, W.F.; Marriel, I.E.; Casela, C.R. Detection of a bacterium associated with a leaf spot disease of maize in Brazil. Journal of Phytopatology, Berlim, v. 149, n. 5, p. 275-279, 2001.

8. Paccola-Meirelles, L.D.; Meirelles, W.F.; Parentoni, S.N.; Marriel, I.E.; Ferreira, A.S.; Casela, C.R. Reaction of maize inbred lines to a bacterium, Pantoea ananas, isolated from Phaeosphaeria leaf spot lesions. Crop Breeding and Applied Biotechnology, Londrina/PR, v.2, n.4, p. 587-590, 2002.

9. Pinto, N.F.J.A. Produção de picnídios de Phyllosticta sp. “in vivo" e "in vitro"em folhas de milho tratadas com fungicidas. Fitopatologia Brasileira, Brasília, v.20, supl. p.333, 1995.

10. Pinto, N.F.J.A. Eficiência de fungicidas no controle de doenças foliares do milho. Summa Phytopathologica, Jaboticabal, v.23, n. 3/4, p. 271-274, 1997.

11. Pinto, N.F.J.A. Eficiência de doses e intervalos de aplicação de fungicidas no controle da mancha foliar do milho provocada por Phaeosphaeria maydis Rane, Payak \& Renfro. Ciências e Agrotecnologia, Lavras, v.23, n.4, p.1006-1009, 1999.

12. Pinto, N.F.J.A. Controle químico de doenças foliares em milho. Revista Brasileira de Milho e Sorgo, Sete Lagoas, v.3, n.1, p.134-138, 2004.

13. Pinto, N.F.J.A.; Fernandes, F.T. Avaliação de fungicidas no controle da mancha foliar de milho causada por Phyllosticta sp. (Phaeosphaeria maydis). Fitopatologia Brasileira, Brasília, v.20, supl., p.333, 1995.

14. Pinto, N.F.J.A.; Fernandes, F.T.; Oliveira, E. Milho (Zea mays L.): Controle de doenças. In: Vale, F.X.R.; Zambolim, L. (Ed.). Controle de doenças de plantas: grandes culturas, Viçosa: Universidade Federal de Viçosa, 1997. v. 2, p. 821-864.

15. Rane, M.S.; Payak, M.M.; Renfro, B.L. The Phaeosphaeria leaf spot of maize. Indian Phytopathologic Society Bulletin. New Delhi, India, v. 3, p. 7-10, 1965. 